Солодухина Ольга Ивановна

кандидат экономических наук, старший преподаватель кафедры таможенного дела и мировой экономики

Юго-Западного государственного университета

\section{АНАЛИЗ ЭФФЕКТИВНОСТИ ФОРМИРОВАНИЯ И ИСПОЛЬЗОВАНИЯ РЕГИОНАЛЬНЫХ АКТИВОВ}

Аннотация:

В статье приведены основные результаты комплексной оценки эффективности наиболее ценного регионального актива - трудового потенциала субъектов Центрально-Черноземного экономического района (ЦЧЭР) за 2010-2016 г2. Актуализация данной проблемы связана с необходимостью совершенствования государственной политики в сфрере использования региональных активов. Использован методический подход, основанный на включении в структуру исследуемой категории потенциала здравоохранения, а также социального, морально-нравственного, образовательного потенциалов. Результаты оценки свидетельствуют о низкой эффективности системы управления трудовым потенциалом региона и обусловлены наличием ряда проблем, вызванных демографическим кризисом, деформациями в трудовом поведении населения, так как большинство управленческих решений в отношении трудового потенциала направлено на решение оперативных задач и не носит cmратегического характера. Анализ формирования и эффективности использования трудового потенциала выявил необходимость разработки инструментария государственной политики, которая представляет собой комплекс мероприятий по вовлечению в систему взаимодействия не только экономических агентов и органов муниципальной власти, но и социально активных групп, формирующих институты публичного управления регионального уровня. Это позволит повысить деловую активность, привлекательность региона для бизнеса, его прозрачность, снизить удельные затраты на производство продукции, обеспечит условия роста занятости, повышение производительности труда и будет способствовать устойчивому развитию территорий.

Ключевые слова:

анализ, региональные активы, трудовой потенциал, государственная политика в сфере рационального использования региональных активов.
Solodukhina Olga Ivanovna

PhD in Economics, Senior Lecturer, Customs Affairs and World Economy Department,

Southwest State University

\section{ANALYSIS OF THE EFFECTIVE DEVELOPMENT AND USE OF REGIONAL ASSETS}

\begin{abstract}
Summary:
The study presents the comprehensive performance assessment of the most valuable regional asset that is the labor capacity of entities in Central Black Earth Economic Region for 2010-2016. The relevance of this issue is explained by the necessity of improving the state policy in the sustainable use of regional assets. Studying the labor potential, the author reviews healthcare, social, moral, ethical, and educational capacities as well. The evaluation findings demonstrate the inefficiency of labor potential management system in the region under review. It is caused by the demographic crisis, alterations in labor behavior as many managerial decisions on labor capacity are not strategic and are to address the challenges. The analysis of the effective development and use of labor potential reveals the need to develop public policy tools. This policy is a set of activities conducive to interaction between economic agents, municipal authorities and socially active groups that create the institutions of public administration at the regional level. This fact will increase business activity, business attractiveness and transparency of the region, reduce production costs, ensure employment and labor productivity growth and will contribute to the sustainable territorial development.
\end{abstract}

Keywords: analysis, regional assets, labor potential, state policy in the sustainable use of regional assets.

Современное состояние и уровень развития региональной экономики зачастую фрормируются на основе исторических реалий и условий функционирования в совокупности с глобальными тенденциями национальной политики. При этом устойчивое развитие региона обеспечивается за счет равновесия между социально-экономическими и природно-географическими фракторами. Новые ориентиры и задачи, стоящие перед экономикой России, определили в качестве приоритетной проблему рационального использования региональных активов - системы сосредоточенных на территории региона ресурсов, которые используются или могут быть оперативно задействованы в хозяйственной деятельности региона в целях получения или увеличения прибыли, повышения уровня и качества жизни населения региона, удовлетворения других потребностей субъектов региональной экономики, а также воспроизводства активов региона [1, с. 48]. 
Любая стратегия обеспечения эффективности использования региональных активов в первую очередь должна содержать индикаторы и параметры, позволяющие контролировать и реализовывать политические решения. В связи с этим возникает необходимость получения достоверных оценок их фрормирования и эффективности использования. В условиях функционирования и развития постиндустриального общества, изменения сущности и значимости человека как новой силы общественного прогресса, дефицита одних категорий работников (высококвалифицированных рабочих, специалистов среднего звена линейных подразделений) и избытка других, что способствует усилению диспропорции структуры экономики и сферы образования, на первый план выходят нематериальные региональные активы, важнейшим из которых является трудовой потенциал региона как ресурс повышения результативности социально-экономического развития регионов и страны в целом, в том числе повышения уровня и качества жизни населения. Трудовой потенциал региона характеризует способность населения осуществлять трудовую деятельность [2].

В связи с вышеизложенным анализ эффективности использования региональных активов осуществлен на примере оценки формирования и реализации трудового потенциала субъектов Центрально-Черноземного экономического района (ЦЧЭР) (период исследования - 2010-2016 гг.), которая произведена на основе использования методического подхода, предполагающего включение в структуру исследуемой категории потенциала здравоохранения, а также социального, морально-нравственного, образовательного потенциалов (рисунок 1).

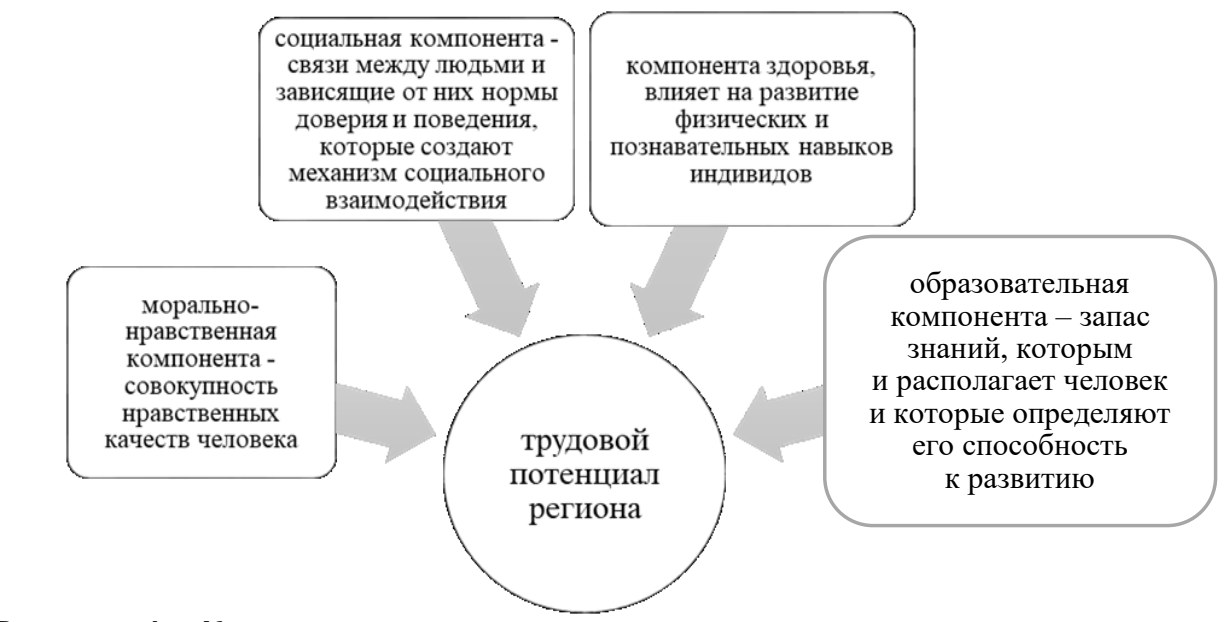

\section{Рисунок 1 - Компонентная структура трудового потенциала региона}

Совокупность показателей для оценки эффективности формирования и использования трудового потенциала региона сформирована на основе подхода к трактовке понятия «трудовой потенциал» как комплекса локализованных на территории региона человеческих ресурсов, обладающих запасом знаний, умений, практических навыков, творческих и мыслительных способностей, мотиваций, морально-нравственных принципов и культурного развития, которые посредством осуществления трудовой деятельности могут быть вовлечены в воспроизводственные процессы и в результате приносить прибыль и удовлетворять другие потребности его носителей.

В целях обеспечения сопоставимости данных осуществлено их нормирование методом линейного масштабирования, затем были рассчитаны интегральные показатели уровня фрормирования и использования трудового потенциала региона (формулы 1, 2).

$$
\begin{aligned}
& I_{\mathrm{T}_{\phi}}=\sqrt[4]{I_{\mathrm{O}_{\phi}} * I_{3_{\phi}} * I_{\mathrm{C}_{\phi}} * I_{\mathrm{MH}_{\phi}}}, \\
& I_{\mathrm{T}_{\mathrm{p}}}=\sqrt[4]{I_{\mathrm{O}_{\mathrm{p}}} * I_{3_{\mathrm{p}}} * I_{\mathrm{C}_{\mathrm{p}}} * I_{\mathrm{MH}_{\mathrm{p}}}},
\end{aligned}
$$

где $I_{\mathrm{T \Pi}_{\mathrm{p}}}$ - реализованный трудовой потенциал региона; $I_{\mathrm{T \Pi}_{\phi}}$ - сформированный трудовой потенциал региона; $I_{\mathrm{O}_{\phi(p)}}$ - сформированная (реализованная) образовательная составляющая трудового потенциала региона; $I_{3_{\phi(p)}}$ - сфрормированные (реализованные) факторы здоровья; $I_{\mathrm{C}_{\phi(p)}}-$ сформированная (реализованная) социальная составляющая трудового потенциала региона; $I_{\mathrm{MH}_{\phi(p)}}$ - сфрормированная (реализованная) морально-нравственная составляющая трудового потенциала региона.

Оценка эффективности использования трудового потенциала региона осуществлена посредством применения метода анализа издержек и результативности (cost - effectiveness analysis CEA) [3, c. 24]. 
Результаты исследования уровня формирования и использования трудового потенциала в субъектах Центрально-Черноземного экономического района показывают схожий уровень развития исследуемой категории (рисунок 2).

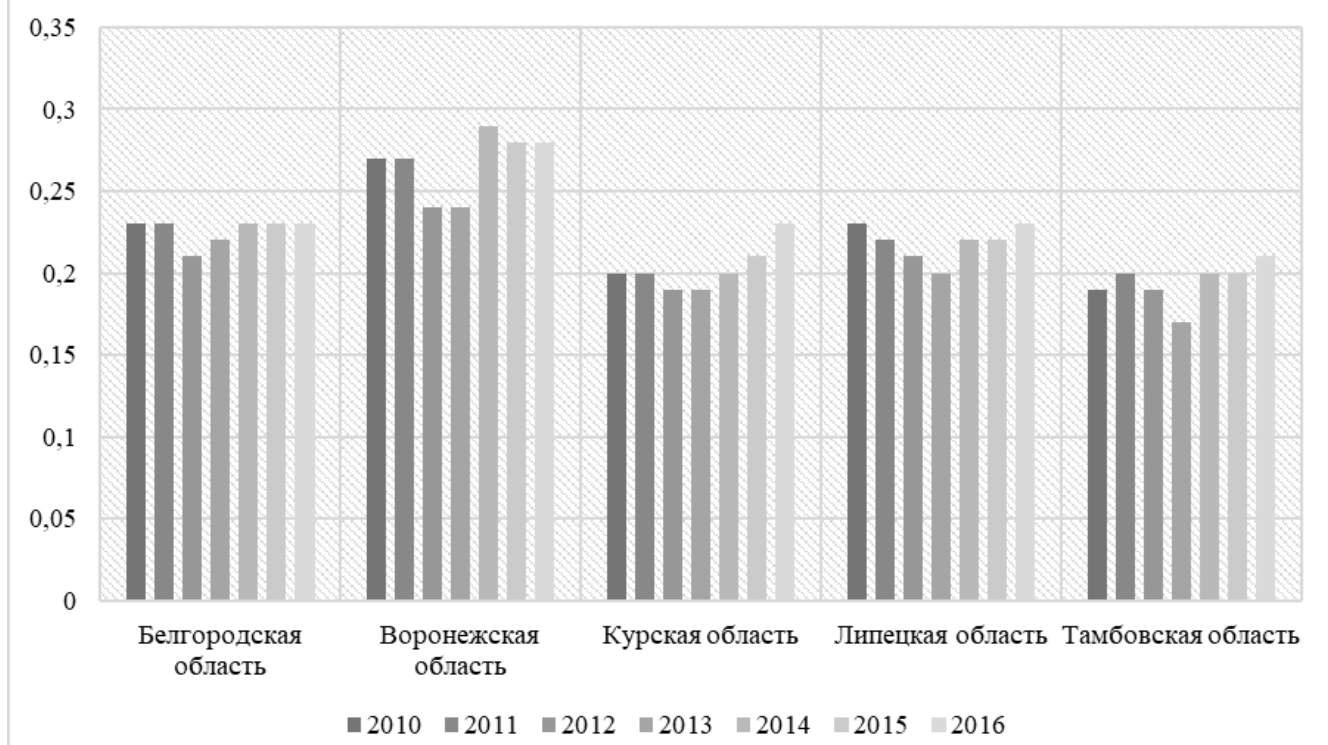

Рисунок 2 - Уровень формирования трудового потенциала ЦЧЭР (2010-2016)

В разрезе структурных компонентов трудового потенциала наиболее высокие показатели достигнуты в части формирования и использования социальной компоненты трудового потенциала регионов ЦЧЭР. Однако низкие показатели фрормирования и использования других элементов трудового потенциала нивелируют достигнутые относительно высокие результаты в социальной сфере. К примеру, в Тамбовской области, согласно официальным данным Федеральной службы государственной статистики за исследуемый период [4], отсутствуют разработанные передовые технологии и самая низкая инновационная активность организаций в ЦЧЭР, что объясняет самый низкий уровень использования образовательной компоненты трудового потенциала.

Высокие показатели реализации образовательной компоненты трудового потенциала достигнуты в Белгородской, Курской и Липецкой областях, что свидетельствует об эффективности деятельности организаций образовательной и научной сферы, служб занятости населения и т. д.

Среди субъектов Центрально-Черноземного экономического района самый высокий уровень формирования трудового потенциала достигнут в Воронежской области, но результаты оценки использования трудового потенциала - одни из самых низких, что говорит о неэффективной деятельности предприятий и органов государственной власти региона (рисунок 3).

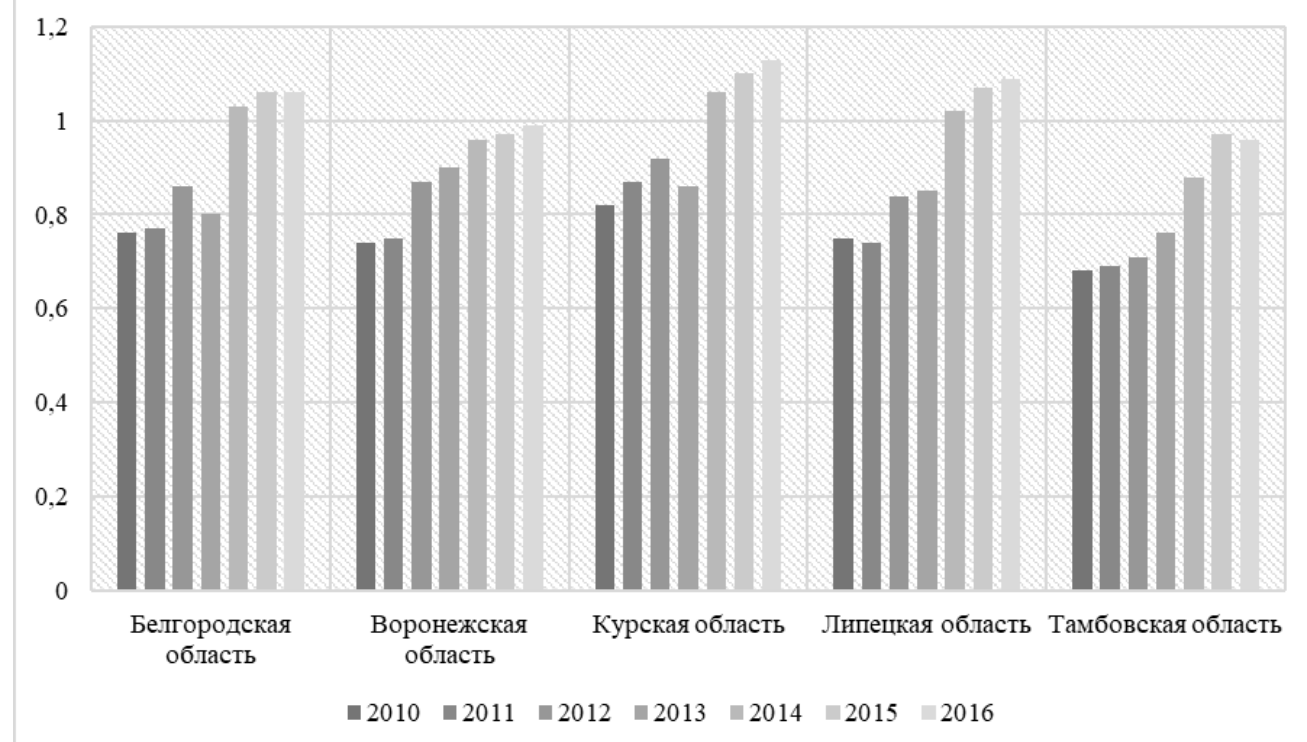

Рисунок 3 - Эффективность использования трудового потенциала субъектов ЦЧЭР (2010-2016) 
Рассматриваемые регионы, исходя из полученных результатов исследования, можно объединить в группы по уровням эффективности использования трудового потенциала (таблица 1).

Таблица 1 - Группировка регионов ЦЧЭР по уровням эффективности использования трудового потенциала (2016)

\begin{tabular}{|l|c|}
\hline $\begin{array}{c}\text { Уровень эффективности использования трудового } \\
\text { потенциала региона (количественная оценка) }\end{array}$ & \multicolumn{1}{c|}{ Наименование региона } \\
\hline Высокий $\left(4<I_{\ni \Phi_{n}}<+\infty\right)$ & - \\
\hline Выше среднего $\left(3<I_{э \Phi_{n}}<3,9\right)$ & - \\
\hline Средний $\left(2<I_{\ni \Phi_{и}}<2,9\right)$ & $\begin{array}{l}\text { Белгородская область, Курская область, } \\
\text { Липецкая область }\end{array}$ \\
\hline Ниже среднего $\left(1<I_{\ni \Phi_{n}}<1,9\right)$ & Воронежская область, Тамбовская область \\
\hline Низкий $\left(0<I_{\ni \Phi_{и}}<0,9\right)$ &
\end{tabular}

Результаты комплексной оценки эффективности формирования и использования трудового потенциала регионов ЦЧЭР обусловлены наличием ряда проблем, вызванных демографическим кризисом, деформациями в трудовом поведении населения, и свидетельствуют о низкой эффективности функционирования системы управления трудовым потенциалом региона. Большинство управленческих решений в отношении трудового потенциала направлено на решение оперативных задач и не носит стратегического характера.

Анализ формирования и эфффективности использования трудового потенциала, рассматриваемого как наиболее ценный региональный актив, выявил необходимость разработки инструментария государственной политики в сфере рационального использования региональных активов. Государственная политика представляет собой комплекс мероприятий по вовлечению в систему взаимодействия не только экономических агентов, функционирующих на территории региона, и органов муниципальной власти, но и социально активных групп, фрормирующих институты публичного управления регионального уровня. С этой позиции рост заинтересованности в совместных усилиях по развитию экономического потенциала региона позволит повысить деловую активность, привлекательность региона для бизнеса, его прозрачность, обеспечит условия роста занятости. Формирование и реализация указанной политики позволит снизить удельные затраты на производство продукции, обеспечит повышение производительности труда, эффективности функционирования регионального хозяйственного комплекса и экономики в целом, будет способствовать устойчивому развитию территорий.

\section{Ссылки:}

1. Солодухина О.И. Экономическая сущность и структура региональных активов // Современные достижения и разработки в области экономики и менеджмента : сборник научных трудов по итогам международной научно-практической конференции. Оренбург, 2016. С. 47-51.

1. Mincer J. The Production of Human Capital and the Lifecycle of Earnings: Variations on a Theme [Электронный ресурс] : NBER Working Paper no. 4838. 1994. URL: http://www.nber.org/papers/w4838 (дата обращения: 12.11.2017).

2. Айзерман М.А., Алескеров Ф.Т. Выбор вариантов: основы теории. М., 1990. 236 с.

3. Федеральная служба государственной статистики [Электронный ресурс]. http://www.gks.ru/ (дата обращения: 12.11.2017).

\section{References:}

Aizerman, MA \& Aleskerov, FT 1990, The choice of options: the foundations of the theory, Moscow, 236 p., (in Russian) Mincer, J 1994, The Production of Human Capital and the Lifecycle of Earnings: Variations on a Theme: NBER Working Paper no. 4838, viewed 12 November 2017, <http://www.nber.org/papers/w4838>, https://doi.org/10.3386/w4838.

Solodukhina, OI 2016, 'The economic essence and structure of regional assets', Sovremennyye dostizheniya i razrabotki v oblasti ekonomiki i menedzhmenta: sbornik nauchnykh trudov po itogam mezhdunarodnoy nauchno-prakticheskoy konferentsii, Orenburg, pp. 47-51, (in Russian). 